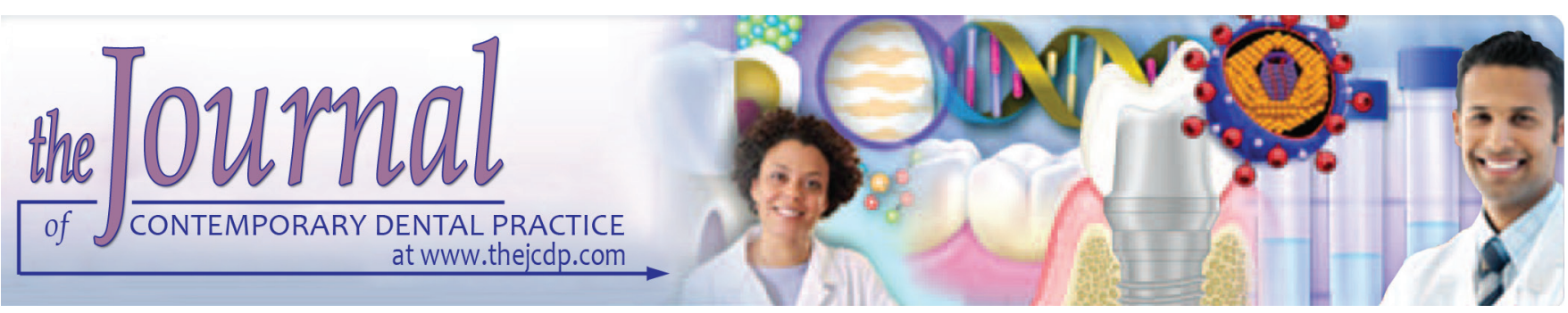

\title{
Most Frequent Oral Lesions in Patients with Type 2 Diabetes Mellitus
}

\author{
${ }^{1}$ Micheline S Trentin, ${ }^{2}$ Georgia Verardi, ${ }^{3}$ Michele De C Ferreira, ${ }^{4}$ João P de Carli, ${ }^{5}$ Soluete 0 da Silva \\ ${ }^{6}$ Igor FP Lima, ${ }^{7}$ Luiz R Paranhos
}

\section{ABSTRACT}

Aim: Type 2 diabetes mellitus (DM2) is a chronic disease caused by the underproduction of insulin in the organism and it is considered a risk factor to periodontal disease.

Materials and methods: This study performed a cross-sectional research on the main oral changes in patients with DM2 and nondiabetics, in Passo Fundo, Rio Grande do Sul, Brazil. The sample included 116 patients examined at the Diabetes Outpatient Clinic of the School of Medicine of the University of Passo Fundo (UPF) and 134 nondiabetic patients examined at the Examinations, Triage, and Emergency Sector of the School of Dentistry of UPF. Inclusion criteria for the study were patients over 35-years old, diagnosed with DM2 for more than 2 years. The same criteria were used for the control group, except for the presence of diabetes. Data collected were analyzed by Statistical Package for the Social Sciences 18.0 for Windows ${ }^{\mathrm{TM}}$ software and the Chi-square test at $5 \%$ significance. This study showed that, overall, oral lesions were more prevalent in diabetic patients.

Results: The stomatological manifestations observed more frequently in such patients were pseudomembranous candidiasis, lichen planus, lingual varices, xerostomia, and prosthetic stomatitis $(p>0.001)$.

Conclusion: Therefore, based on the sample investigated, it is concluded that patients with DM2 present higher prevalence of oral lesions when compared with nondiabetics.

Clinical significance: It is important for the dentist to know about oral lesions because they may allow either early diagnosis in

\footnotetext{
1,4,5 Department of Dentistry, University of Passo Fundo, Passo Fundo, Rio Grande do Sul, Brazil

${ }^{2}$ Department of Dentistry, Community University of the Chapecó Region, Chapecó, Santa Catarina, Brazil

${ }^{3}$ Department of Dentistry, Faculdade Meridional, Passo Fundo Rio Grande do Sul, Brazil

${ }^{6,7}$ Department of Dentistry, Federal University of Sergipe Lagarto, Sergipe, Brazil
}

Corresponding Author: Micheline S Trentin, Department of Dentistry, University of Passo Fundo, Passo Fundo, Rio Grande do Sul, Brazil, Phone: +555430451201, e-mail: tmicheline@upf.br patients unaware of this condition or help diagnosing a potential decompensation. Moreover, oral lesions may represent a potential gateway for infectious agents, and the dentist may restrain this condition by performing treatment as early as possible.

Keywords: Case control study, Diabetes mellitus, Diagnosis, Oral manifestations.

How to cite this article: Trentin MS, Verardi G, De C Ferreira M de Carli JP, da Silva SO, Lima IFP, Paranhos LR. Most Frequent Oral Lesions in Patients with Type 2 Diabetes Mellitus. J Contemp Dent Pract 2017;18(2):107-111.

Source of support: Nil

Conflict of interest: None

\section{INTRODUCTION}

Diabetes mellitus (DM) is a chronic disease that represents a disorder in the metabolism of glucose, carbohydrates, lipids, and proteins, and it is characterized by the inability of the organism to resist to or produce insulin. ${ }^{1,2}$ Diabetic patients present classic symptoms of the triad: Polydipsia, polyuria, and polyphagia, which are often associated with chronic fatigue and weight loss. ${ }^{3}$ Diabetes is one of the most prevalent diseases in the world, and it has been dramatically increasing over the last decades. ${ }^{4}$ Populations tend to show a constant increase in the incidence of the disease as age progresses. ${ }^{5}$ It is estimated that 382 million people in the world suffer from diabetes, ${ }^{6}$ which is one of the main causes of mortality and morbidity. ${ }^{7}$ There are two types of diabetes. Type 1 results from the underproduction of insulin that occurs by beta cell destruction in the pancreas. ${ }^{3}$ On the other hand, Type 2 DM (DM2) is characterized by resistance to insulin, whereas aging, obesity, and family history are the main etiological factors. ${ }^{5}$ The change in cell response is the result from the deficiency of insulin receptors. $^{2}$ Type $2 \mathrm{DM}$ is the most common form of the disease, accounting for about $90 \%$ of all cases. ${ }^{8,9}$ 
Due to its high prevalence worldwide, DM carriers often visit dental offices. ${ }^{7}$ Several studies ${ }^{4,9-12}$ have affirmed the relationship of DM with oral pathological processes, where periodontal disease is mostly associated. Several factors contribute to improve this relationship. ${ }^{12}$ The production of glycation end products, changes the structure and metabolism of collagen, changes in immunological response, and interleukins activation are among the most common actions in decompensated diabetic patients, effectively contributing to the progression of periodontal disease. ${ }^{12}$ Thus, the maintenance of periodontal tissue health contributes to an improved metabolic control, reducing the need for insulin and the levels of glycosylated hemoglobin. ${ }^{6,7}$

Besides periodontal disease, several other oral manifestations are often associated with DM. ${ }^{9}$ Hyposalivation, another common oral manifestation from the systemic condition, is characterized by the decreased production of saliva because of the hypofunction of salivary glands. ${ }^{13}$ Changes in the parenchyma of these glands affect cell activity, reducing enzyme action, and causing disorders in saliva production. ${ }^{14}$ Ulcers, cheilitis, and fissured tongue may be consequences presented in the oral cavity of diabetic patients. ${ }^{9}$ Moreover, the change of oral microbiota in diabetic patients makes them prone to infections by Candida albicans. This predisposition may be due to xerostomia or immunosuppression. Xerostomia is considered one of the main signs of DM. Its occurrence causes discomfort and facilitates the establishment and development of carious disease. ${ }^{15}$ Therefore, this study aimed to identify whether the prevalence and severity of oral diseases are higher in patients with DM2 than in nondiabetic patients.

\section{MATERIALS AND METHODS}

Before this research was performed, this study was approved by the Research Ethics Committee in Human Beings under protocol number $797 / 2005$, and the participants signed an informed consent form regarding the objectives of the project.

The total sample studied (250 patients) included a control group and an experimental group. At the Diabetes Outpatient Clinic of the School of Medicine [FM - University of Passo Fundo (UPF)], 116 patients were examined and formed the experimental group. At the Examinations, Triage, and Emergency Sector of the School of Dentistry (SETU/FO-UPF), 134 nondiabetic patients were examined and formed the control group. Inclusion criteria of the study were patients over 35 years old with DM2 for the experimental group and nondiabetics for the control group. Pregnant patients were excluded from the study.
The DM was diagnosed through the criteria proposed by the World Health Organization ${ }^{16}$ and by the Guidelines of the Brazilian Society of Diabetes. ${ }^{17}$ According to fasting glycemia and 2 hours after $75 \mathrm{mg}$ glucose overload (postprandial glycemia), the individuals were classified into the following categories: Compensated patients (fasting glycemia ranging between 70 and $110 \mathrm{mg} / \mathrm{dL}$ of blood, and postprandial glycemia up to $170 \mathrm{mg} / \mathrm{dL}$ of blood); compensated patients, but with decreased tolerance to glucose (fasting glycemia ranging from 110 to $126 \mathrm{mg} / \mathrm{dL}$ of blood and postprandial glycemia up to 170 to $199 \mathrm{mg} / \mathrm{dL}$ of blood); decompensated patients (fasting glycemia higher than or equal to $126 \mathrm{mg} / \mathrm{dL}$ of blood, and postprandial glycemia higher than or equal to 200 $\mathrm{mg} / \mathrm{dL}$ of blood).

For clinical examination, all anatomical sites were analyzed (lips, tongue, gingiva, and palate) and information was filled out on proper clinical records by two previously trained examiners. In addition, a questionnaire was applied to assess the following variables: Gender, age, socioeconomic status, level of oral hygiene, quality of saliva, use of insulin or other antidiabetics, allergies to medicines or other substances, smoking habit, normality of blood pressure, presence of cardiovascular and/ or renal diseases, use of dental prosthesis, daily tooth brushing frequency, use of dental floss, number of active caries, periodontal disease, and xerostomia.

Before this study was performed, an intra and interexaminer training was carried out, as well as a pilot study with 20 patients (10 patients from the SETU/FO-UPF, and 10 patients with DM2 from the diabetes outpatient clinic of the FM-UPF). Kappa test was used to assess interexaminer reproducibility, which resulted in $80 \%$ concordance.

Data collected were statistically analyzed by the Statistical Package for the Social Sciences (18.0 for Windows ${ }^{\mathrm{TM}}$ ) software with a qualitative research focus, and statistical analysis was performed through the chisquare test at $5 \%$ and relative risk index (odds ratio).

\section{RESULTS}

Table 1 shows data concerning age, gender, and presence or absence of DM2 in the research participants. This table showed that 96 individuals were men and 154 were women $(p=0.052)$. Among diabetic patients, only 33 were between 35- and 50-year-old and 83 were over 50-year-old.

Most diabetic patients examined were over 50-yearold $(n=83)$, while nondiabetics $(n=79)$ were between 35- and 50-year-old, with statistically significant difference $(p=0.00)$. There was no statistical difference when relating gender to the presence or absence of diabetes $(p=0.052)$, where 64 were women and 52 were men. 
Most Frequent Oral Lesions in Patients with Type 2 Diabetes Mellitus

Table 1: Data concerning age and gender of patients examinated according to the chi-square test at $5 \%$ significance

\begin{tabular}{|c|c|c|c|c|c|c|c|}
\hline \multirow[b]{2}{*}{ Age } & \multicolumn{2}{|c|}{$D M 2$} & \multirow[b]{2}{*}{ Total } & \multirow[b]{2}{*}{ Gender } & \multicolumn{2}{|c|}{$D M 2$} & \multirow[b]{2}{*}{ Total } \\
\hline & No & Yes & & & No & Yes & \\
\hline 35-50-year-old & 79 & 33 & 112 & Male & 44 & 52 & 96 \\
\hline Over 50-year-old & 55 & 83 & 138 & Female & 90 & 64 & 154 \\
\hline Total & 134 & 116 & $\begin{array}{l}250 \\
{ }^{*} P=0 .\end{array}$ & Total & 134 & 116 & $\begin{array}{l}250 \\
P=0.052\end{array}$ \\
\hline
\end{tabular}

*Statistically significant value

Table 2: Relationship between the presence of pseudomembranous candidiasis and DM2 regarding the use of insulin according to the chi-square test at $5 \%$ significance

\begin{tabular}{llll}
\hline Pseudomembranous & \multicolumn{2}{l}{ Regular insulin use } & \\
\cline { 2 - 3 } candidiasis & No & Yes & Total \\
\hline No & & & \\
$\quad$ Diabetes & & & \\
$\quad$ No & 78 & - & 78 \\
$\quad$ Yes & 40 & 52 & 92 \\
$\quad$ Total & 118 & 52 & 170 \\
Yes & & & \\
$\quad$ Diabetes & 19 & - & 19 \\
$\quad$ No & 2 & 6 & 8 \\
$\quad$ Yes & 21 & 6 & ${ }^{*} \mathrm{P}=0.00$ \\
\hline$\quad$ Total & & & \\
\hline
\end{tabular}

*Statistically significant value

The risk index of the sample indicated that patients over 50-year-old had 3.613 times higher risk of developing DM2 than patients from 35- to 50-year-old. The confidence interval obtained by logistic regression for the association between DM2 and age was 2.126 to 6.139 .

Insulin-dependent diabetic patients presented higher rate of oral pseudomembranous candidiasis than diabetic patients who did not use insulin as shown in Table 2. Table 3 shows that patients with DM2 presented higher prevalence of xerostomia than nondiabetic patients.

Diabetic patients who used complete upper denture presented higher prevalence of prosthetic stomatitis than nondiabetics $(\mathrm{p}=0.006)$. The estimated risk and confidence interval obtained by logistic regression for the association between DM2 and prosthetic stomatitis in complete upper denture users was 7.442 times higher, with confidence interval of 2.971 .

Table 4 shows that from 116 diabetic patients examined, 7 presented clinical signs of oral reticular lichen

Table 4: Relationship between the presence of lichen planus and DM2, according to the chi-square test at $5 \%$

\begin{tabular}{clll}
\hline & \multicolumn{2}{c}{ Oral lichen planus } & \\
\cline { 2 - 3 } & No & Yes & Total \\
\hline Diabetes & & & \\
No & 134 & - & 134 \\
Yes & 109 & 7 & 116 \\
\hline Total & 243 & 7 & ${ }^{*} \mathrm{P}=0.004$ \\
\hline
\end{tabular}

*Statistically significant value
Table 3: Relationship between the presence of xerostomia and DM2, according to the chi-square test at 5\%

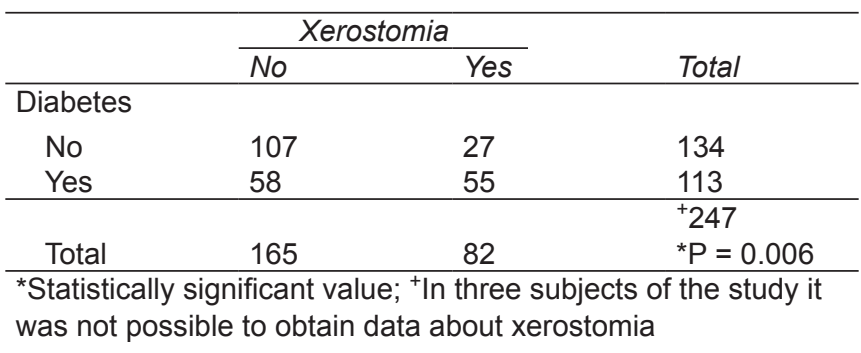

planus, while none of the nondiabetic patients presented such disease.

\section{DISCUSSION}

This study aimed to identify whether the prevalence and severity of oral diseases are higher in patients with DM2 than in nondiabetic patients. Hence, it is possible to verify that the risk index for the development of oral lesions, such as prosthetic stomatitis, xerostomia, and pseudomembranous candidiasis was higher in diabetic patients than in nondiabetics, especially for patients over 50-year-old, who demanded more attention from dentists regarding this disorder.

The DM2 is a highly prevalent chronic disease characterized by resistance to insulin, where aging, obesity, and family history are the main etiological factors. ${ }^{2}$ Such condition was described as a new global epidemic, constituting one of the main public health challenges of the 21 st century. ${ }^{18}$ It is estimated that 382 million people in the world suffer from diabetes, ${ }^{6}$ which is one of the main causes of mortality and morbidity. ${ }^{7}$ Hence, a series of oral lesions have been associated with DM2.

The endocrine system plays an essential role in regulating several bodily processes through secretion and regulation of hormones, including those inside the oral cavity. ${ }^{19}$ More than $20 \%$ of adults over 60 -year-old have diabetes, and Type 2 is more prevalent in this group. Besides the increased potential to develop periodontitis, diabetic patients may present other oral complications related to diabetes, such as xerostomia, oral burning syndrome, candidiasis, defective wound healing, increased tendency to infections, decreased salivary flow, and salivary gland enlargement. ${ }^{4,19}$ Such affirmations agree with the findings of this study, considering that in our sample, 
patients over 50-year-old presented significantly more DM2 than younger patients $(p=0.00)$, showing 3.613 times higher risk of developing the endocrine disorder (Table 1).

It is known that diabetic patients have a higher risk of acquiring opportunistic infections since there are changes in oral microbiota and the immunological system. ${ }^{15}$ Such increased risk may also be due to the presence of xerostomia or immunosuppression. ${ }^{15}$ The primary cause is related to reduced salivary flow, which leads to the reduction of immunoglobulin levels in saliva, decreasing the immunological defense mechanism mediated by the humoral factor for controlling Candida infection. Therefore, we verified a higher rate of pseudomembranous candidiasis in insulin-dependent diabetic patients that in diabetic patients who did not use insulin $(p=0.00)$ (Table 2). Similarly, Martinez et a ${ }^{20}$ verified that $55.1 \%$ of individuals had Candida, when examining a sample of 141 diabetic patients in Mexico. Another study ${ }^{21}$ with similar objectives verified the prevalence of pseudomembranous candidiasis in diabetic patients when compared with nondiabetics. Thus, it is true to indicate that such pathology is one of the most frequent conditions in this population group.

Xerostomia is characterized by decreased salivary secretion, and this condition is considered one of the main signs of DM. ${ }^{15}$ Its occurrence causes discomfort and facilitates the establishment and development of carious disease. ${ }^{15}$ Several studies ${ }^{13,21-23}$ have reported the association between xerostomia and DM2. A study ${ }^{22}$ including 391 patients with DM2 and 391 individuals constituting the control group suggested that decompensated patients present a significantly higher prevalence than metabolically controlled patients $(\mathrm{p}<0.05){ }^{22}$ The information obtained in this study agree with such findings since we observed that patients with DM2 presented higher prevalence of xerostomia $(\mathrm{n}=55)$ than nondiabetic patients $(\mathrm{n}=27)(\mathrm{p}=0.00)($ Table 3$)$. On the contrary, by studying a universe of 30 patients, authors ${ }^{21}$ found the presence of xerostomia in only one patient, which disagrees with our work. Such a contradiction may be explained by the low sample number assessed by the study in question. It is worth noting that this study did not measure the amount of saliva in patients, and the presence or absence of xerostomia was determined by the sensation of "dry mouth" reported by patients.

The use of complete upper denture is relatively common in older patients. However, the deficiencies of such appliance, yeast infections, or poor oral hygiene may promote prosthetic stomatitis. ${ }^{24}$ This lesion is characterized by an erythematous lesion confined to the prosthesis area and may present painful symptomatology. ${ }^{24}$ In our study, diabetic patients with complete upper denture presented more prosthetic stomatitis than nondiabetics $(p=0.006)$. Several studies ${ }^{19,22}$ corroborate our results. Al-Maweri et $\mathrm{al}^{22}$ found highly significant results for prosthetic stomatitis in diabetics compared with nondiabetics $(p=0.018)$. Thus, it is possible to suggest there is a significant association between metabolic control of DM2 and oral lesion since diabetic patients with complete upper denture showed 7.442 times higher risk than nondiabetics for developing prosthetic stomatitis.

In this work, from the 116 diabetic patients examined, 7 presented clinical signs of oral lichen planus, while none of the nondiabetic patients presented such disease. Thus, it was possible to observe a significant relationship between DM2 and oral lichen planus $(p=0.004)$. In a study ${ }^{25}$ with 80 carriers of lichen planus, wherein 16 $(20 \%)$ were diabetics, the results also showed a statistically significant relationship ( $\mathrm{p}=0.001$ ), agreeing with this study. Moreover, the said authors ${ }^{25}$ suggested that the duration of lichen planus lesions in diabetic patients was significantly longer when compared with the lesions in nondiabetic patients. This is probably caused by the difficulty of tissue repair of lesions, which is considered a typical characteristic of diabetic patients.

Thus, our work highlights a significant association between DM2 and oral lesions, especially pseudomembranous candidiasis, lichen planus, lingual varices, xerostomia, and prosthetic stomatitis ( $p>0.001)$. We believe that the results, hereby, reported are of vital importance for establishing new conducts with greater emphasis on diabetic patients. Hence, further studies should be performed to confirm and reinforce such findings.

\section{CONCLUSION}

The patients with DM2 from the sample studied presented higher risk index for developing oral lesions than nondiabetics, especially pseudomembranous candidiasis, lichen planus, lingual varices, xerostomia, and prosthetic stomatitis.

\section{REFERENCES}

1. Abdulrahman KA. Diabetes mellitus and its oral complications: A brief review. Pak Oral Dent J 2006;26(1):97-100.

2. Gopal D, Malathi N, Reddy BT. Efficacy of oral exfoliative cytology in diabetes mellitus patients: a light microscopic and confocal microscopic study. J Contemp Dent Pract 2015 Mar;16(3):215-221.

3. Hamadneh S, Dweiri A. Oral manifestations in controlled and uncontrolled diabetic patients - a study in Jordan. Pak Oral Dent J 2012 Dec;32(3):456-459.

4. Al-Maskari AY, Al-Maskari MY, Al-Sudairy S. Oral manifestations and complications of diabetes mellitus: a review. Sultan Qaboos Univ Med J 2011 May;11(2):179-186.

5. Forouhi NG, Wareham NJ. Epidemiology of diabetes. Medicine (Abingdon) 2014 Dec;42(12):698-702 
6. International Diabetes Federation. Epidemiology and prevention. [cited July 09, 2016]. Available from: http://www.idf. org/epidemiology-prevention.

7. Centers for Disease Control and Prevention. National diabetes statistics report: estimates of diabetes and its burden in the United States. Atlanta: U.S. Department of Health and Human Services; 2014

8. Kudiyirickal MG, Pappachan JM. Diabetes mellitus and oral health. Endocrine 2015 May;49(1):27-34.

9. Nandakumar E. Dental manifestations in diabetic and nondiabetic patients: a review. J Pharm Sci Res 2015;7(7):482-484.

10. Indurkar MS, Maurya AS, Indurkar S. Oral manifestations of diabetes. Clin Diabetes 2016 Jan;34(1):54-57.

11. Gandara BK, Morton TH Jr. Non-periodontal oral manifestations of diabetes: a framework for medical care providers. Diabetes Spectr 2011 Nov;24(4):199-205.

12. Bajaj S, Prasad S, Gupta A, Singh VB. Oral manifestations in type-2 diabetes and related complications. Indian J Endocrinol Metab 2012 Sep;16(5):777-779.

13. Sousa MG, Costa Ade L, Roncalli AG. Clinical study of the oral manifestations and related factors in type 2 diabetics patients. Braz J Otorhinolaryngol 2011 Mar-Apr;77(2):145-152.

14. Chavez EM, Taylor GW, Borrell LN, Ship JA. Salivary function and glycemic control in older persons with diabetes. Oral Surg Oral Med Oral Pathol Oral Radiol Endod 2000 Mar;89(3):305-311.

15. Nirmala SV, Saikrishna D. Dental care and treatment of children with diabetes mellitus: An overview. J Pediatr Neonatal Care 2016;4(2):00134.

16. Guilbert JJ. The world health report 2002 - reducing risks, promoting healthy life. Educ Health (Abingdon) 2003 Jul;16(2):230.
17. Sociedade Brasileira de Diabetes. Estatísticas do diabetes no Brasil e no mundo. [cited October 15, 2016. Available from: http:/ / www.diabetes.org.br/sbdonline/images/docs / DIRETRIZES-SBD-2015-2016.pdf.

18. Sui H, Sun N, Zhan L, Lu X, Chen T, Mao X. Association between work-related stress and risk for Type 2 diabetes: a systematic review and meta-analysis of prospective cohort studies. PLoS One 2016 Aug;11(8):e0159978.

19. Berkey DB, Scannapieco FA. Medical considerations relating to the oral health of older adults. Spec Care Dentist 2013 Jul-Aug;33(4):164-176.

20. Martinez RF, Jaimes-Aveldañez A, Hernández-Pérez F, Arenas R, Miguel GF. Oral Candida spp carriers: its prevalence in patients with type 2 diabetes mellitus. An Bras Dermatol 2013 Mar-Apr;88(2):222-225.

21. Vasconcelos BC, Novaes M, Sandrini FA, Maranhão Filho AW, Coimbra LS. Prevalence of oral mucosa lesions in diabetic patients: a preliminary study. Braz J Otorhinolaryngol 2008 May-Jun;74(3):423-428.

22. Al-Maweri SA, Ismail NM, Ismail AR, Al-Ghashm A. Prevalence of oral mucosal lesions in patients with type 2 diabetes attending Hospital Universiti Sains Malaysia. Malays J Med Sci 2013 Jul;20(4):39-46.

23. Ivanovski K, Naumovski V, Kostadinova M, Pesevska S, Drijanska K, Filipce V. Xerostomia and salivary levels of glucose and urea in patients with diabetes. Prilozi 2012;33(2):219-229.

24. Krishnan PA. Fungal infections of the oral mucosa. Indian J Dent Res 2012 Sep-Oct;23(5):650-659.

25. Atefi N, Majedi M, Peyghambari S, Ghourchian S. Prevalence of diabetes mellitus and impaired fasting blood glucose in patients with Lichen Planus. Med J Islam Repub Iran 2012 Feb;26(1):22-26. 